\title{
ЧЕЛОВЕЧЕСКИЙ КАПИТАЛ В ПЕРСПЕКТИВЕ ЭВОЛЮЦИИ ПРОИЗВОДИТЕЛЬНЫХ СИЛ ОБРАБАТЫВАЮЩЕЙ ПРОМЫШЛЕННОСТИ
}

\section{(ㄷ) 2021 Овсянников Роман Юрьевич}

соискатель, кафедра экономики и управления предприятиями и производственными комплексами Санкт-Петербургский государственный экономический университет, Россия, Санкт-Петербург

E-mail: r.ovsyannikov@academprofi.ru

В настоящей публикации автором обсуждается изменение структуры производственных отношений в обрабатывающей промышленности в рамках консолидации мирового рынка, усиления инновационных и цифровых факторов экономического развития. Сформулированы среднесрочные перспективы трансформации принципов и форм взаимоотношений субъектов хозяйствования с человеческим капиталом. Работа выполнена в рамках плана исследований научной школы СПбГЭУ «Экономика, организация и управление предприятиями, отраслями, комплексами; управление инновациями; экономика оборонно-промышленного комплекса» (руководитель - профессор Карлик А.Е.).

Ключевые слова: экономика, обрабатывающая промышленность, человеческий капитал.

Обрабатывающая промышленность входит в 4-ую промышленную революцию (также формулируемую как «Индустрия 4.0»), горизонтом которой ученые и аналитики определяют среднесрочную перспективу -2025 год. В экономическом контексте она подразумевает трансформацию производительных силы и производственных отношений, новый контекст взаимодействия субъектов хозяйствования с производственным фактором «труд». В условиях экономик «знаний» и «цифровой», фактор осмысляется как человеческий капитал: «...знания, квалификации, навыки и другие качества, которыми обладает индивидуум и которые важны для хозяйственной деятельности» (Glossary of Environment Statistics, [1]). Человеческий капитал рассматривается частью интеллектуального капитала на микроуровне (Coff R.W. [2]), исследуется и формализуется как актив предприятия в экономических контекстах оценки стоимости, дохода, рентабельности, инвестиций, формирования добавленной стоимости. Научное осмысление изменений производственных отношений промышленности в условиях новой экономической формации еще не получило должного внимания в академической среде, поэтому автор сфокусировал внимание (в настоящей публикации) на формализации среднесрочных тенденций и перспектив.

Анализ построен на поиске солидарно видимых учеными и аналитиками перспектив изменений: а) моделей менеджмента предприятий обрабатывающей промышленности; б) требований к профилю человеческого капитала со стороны хозяйствующих субъектов; в) эволюции форм взаимодействия человеческого капитала, средств и предмета труда; г) контрактных моделей с персоналом. Автором проведен анализ ряда источников: «Отчет о глобальном развитии человеческого капитала 2017» (WEF [3]); «Глобальные тренды человеческого капитала» (Deloitte 2017 [4], 2019 [5]); материалы Всемирного Банка [6]); Отчеты Комиссии Евросоюза, 2018 [7] и OECD - «Перспективы занятости» (2019, [8]); «Будущее труда» (2019, [9]) и другие научные и аналитические материалы.

Ключевой вывод по результатам анализа сводится к однозначности изменения структуры производственных отношений под воздействием трех вызовов, стоящих перед обрабатывающей промышленностью в среднесрочной перспективе: рост концентрации глобального рынка, инновации как ключевой фактор конкурентоспособности и цифровая форма средств и предмета труда. Трем обозначенным тенденциям соответствуют 3 перспективы изменений производственных отношений (табл. 1), рассматриваемые в контексте настоящей публикации.

Перспектива 1 - глобальность рынка человеческого капитала. Консолидация мировой обрабатывающей промышленности (48\% [10]: Китай - 20\%, США - 18\%, Япония - 10\%) приводит к усилению миграционных процессов. Рынок труда становится глобальным (Архипов А.Ю. 
Таблица 1. Среднесрочные тенденции обрабатывающей промышленности и встречные перспективы изменения производственных отношений

\begin{tabular}{|l|l|}
\hline $\begin{array}{l}\text { Тенденция обраба- } \\
\text { тывающей промыш- } \\
\text { ленности }\end{array}$ & $\begin{array}{l}\text { Перспектива изменений производственных отноше- } \\
\text { ний (следствие тенденции) }\end{array}$ \\
\hline $\begin{array}{l}\text { Консолидация гло- } \\
\text { бального рынка }\end{array}$ & $\begin{array}{l}\text { Рынок труда становится глобальным, снижение ми- } \\
\text { грационных барьеров человеческого капитала. Гло- } \\
\text { бальный «хэдхантинг». }\end{array}$ \\
\hline $\begin{array}{l}\text { Инновационность } \\
\text { как ключевой фак- } \\
\text { тор конкурентоспо- } \\
\text { собности }\end{array}$ & $\begin{array}{l}\text { Предприятия переходят от процессной к проектной } \\
\text { медели организации. Специалисты становятся парт- } \\
\text { ном горизонте времени и результатов. }\end{array}$ \\
\hline $\begin{array}{l}\text { Цифровая эконо- } \\
\text { мика }\end{array}$ & $\begin{array}{l}\text { Изменение требований к профилю (знаний, навыка, } \\
\text { способностей) человеческого капитала. }\end{array}$ \\
\hline
\end{tabular}

и др. [11]): человеческий капитал формируется на уровне стран, а трудовые ресурсы распределяются согласно пространственной локализации субъектов, центров обрабатывающей промышленности. Данная перспектива объективно выражена среднегодовым приростом уровня мировой трудовой миграции в 12\% (табл. 2). «Мобильность» человеческого капитала, «мобильность талантов» (англ. - talent mobility [8]) рассматривается (WEF [6]) как она из важнейших характеристик в развитии производственных отношений обрабатывающей промышленности. На это указывает также устойчивость (низкая вариативность в ретроспективе 15 лет) показателя отношения затрат на персонал к обороту отраслей обрабатывающей промышленности (выборка Европа и Россия - расчет автора по базе данных базы данных Amadeus*) на уровне 24,4\%, что обеспечивает экономическую устойчивость со средней рентабельность активов - 5,4\%, и соответственно капитала - 24,5\%. Катализом «мобильности» является и «...старение населения стран с развитой экономикой ... (доля нетрудоспособного населения увеличится - автор) с 20\% (1980 год) до 53\% (2050)» (OECD [8]).

Данная перспектива выводит нас на понимание среднесрочной позиции предприятий обрабатывающей промышленности - устойчивость экономического развития обеспечивается взаимодействием с глобальным рынком человеческого капитала. Россия (табл. 2) очень незначительно задействована в мировом рынке трудовых отношений (среднегодовой темп роста трудовой миграции 0,3\%) и это может стать причиной снижения потенциала человеческого капитала в отдельных отраслях обрабатывающей промышленности, и как следствие сдерживающим фактором экономического развития.

* Здесь и далее режим доступа к базе данных Amadeus: https://amadeus.bvdinfo.com в период 2018-2020.

Таблица 2. 10-ти летние и средние в периоде оценки (СТР) темпы трудовой миграции в проекции по странам с различным уровнем дохода (классификация и источник WB*)

\begin{tabular}{|l|r|r|r|r|r|r|r|r|}
\hline Группы & 1960 & 1970 & 1980 & 1990 & 2000 & 2010 & 2015 & СТР \\
\hline Мировой & 71,88 & 78,38 & 93,72 & 152,27 & 172,28 & 221,23 & 243,19 & \\
\hline темпь & & $4 \%$ & $13 \%$ & $46 \%$ & $7 \%$ & $16 \%$ & $10 \%$ & $12 \%$ \\
\hline В том числе по в сумме стран по уровню дохода (классификация WВ) \\
\hline Высокий & 33,10 & 40,83 & 52,13 & 75,91 & 101,17 & 144,58 & 157,94 & \\
\hline темпь & & $10 \%$ & $14 \%$ & $28 \%$ & $16 \%$ & $21 \%$ & $9 \%$ & $15 \%$ \\
\hline Средний & 34,63 & 32,49 & 34,39 & 67,16 & 63,73 & 68,04 & 75,57 & \\
\hline темпы & & $-3 \%$ & $8 \%$ & $76 \%$ & $0 \%$ & $6 \%$ & $11 \%$ & $9 \%$ \\
\hline Низкий & 4,16 & 5,07 & 7,20 & 9,21 & 7,37 & 8,61 & 9,68 & \\
\hline темпь & $6 \%$ & $46 \%$ & $29 \%$ & $-18 \%$ & $19 \%$ & $12 \%$ & $9 \%$ \\
\hline Россия & н/д & н/д & н/д & 11,52 & 11,90 & 11,19 & 11,64 & \\
\hline темпь & & & $0 \%$ & $-4 \%$ & $4 \%$ & $0,3 \%$ \\
\hline
\end{tabular}


Перспектива 2 автором формулируется как смена модели менеджмента в обрабатывающей промышленности от «процессной» к «проектной» (сравнение принципов представлено в табл. 3). Природа данной тенденции - переход к инновационной парадигме экономического развития, обуславливающей сокращение длительности «жизненного цикла продукта», высокие темпы обновления ассортимента, рост инвестиций в НИОКР, дизайн, новые методы маркетинга и продаж.

«Проект, инновации, обмен знаниями» (Brown A.W. и др. [12]) - именно эти 3 принципа лежат в основе перспективной модели организации хозяйственной деятельности субъектов обрабатывающей промышленности. В практическом смысле планирование подразумевает выделение циклов с видимым горизонтом (сроками), бюджетом и ожидаемой экономической эффективностью. Соответственно, взаимодействие предприятия и персонала рассматривается с позиции ограниченных сроков взаимодействия, соответствующих циклу или этапу инновационного проекта. Изменяется и контрактная позиция, предприятия переходят к более сильным мотивационным моделям, построенным на «партнерстве», например, создание консорциума с физическим лицом, тантьема, участие в прибыли проекта (табл. 4). Развиваются сетевые формы отношений с юридическими и физическими лицами, интегрируемыми в проект на отдельных этапах инновационного проекта. Причем, при снижении доли субконтрактинга (OECD [8]) в сетевых моделях растет величина прямых контрактов с физическими лицами на основе «свободного», сдельного контракта (англ. - freelance). «... Каждый 7-9 будет (в перспективе 2025 года будет - автор) самозанятый или работать по временному контракту» (OECD [9]).

Сетевая, проектная модель организации инновационных проектов (в отличии от устаревающей для обрабатывающей промышленности «процессной») имеет выраженное преимущество в отношениях с человеческим капиталом взаимная прозрачность сроков и экономических результатов, высокая мотивация, партнерство. С практической позиции для предприятий меняется логика и содержание хозяйственного планирования: от среднесрочной программы (стратегии) научно-технического развития к построению устойчивой партнерской сети с юридическими и физическими лицами в рамках границ инновационных проектов.

Перспектива 3 формулируется автором как изменение профиля требований к человеческому капиталу при внедрении цифровых решений в основной и вспомогательный циклы обрабатывающей промышленности. «... 40\% новых рабочих мест в мире в период 2005-2016 годов были созданы в отраслях, развивающихся на основе цифровых технологий» (OECD [9]). Трансформация профиля подразумевает, что «...14\% специальностей (будет) сокращено, а $32 \%$ - значительно трансформировано» [4]. Уже сегодня выражен дефицит (табл. 5) человеческого капитала с необходимым профилем знаний, даже в условиях глобальной мобильности (тенденция 1) - «... 60\% работающих имеют недостаточные навыки в сфере инфокоммуникаций» [8].

Таблица 3. Сравнение организационных принципов процессной и проектной (перспективной) модели менеджмента в промышленности. Основано на данных Deloitte [4] и OECD [9]

\begin{tabular}{|l|l|}
\hline Процессная модель & Проектная модель \\
\hline $\begin{array}{l}\text { Отношения нацелены на эф- } \\
\text { фективность и результатив- } \\
\text { ность. }\end{array}$ & $\begin{array}{l}\text { Отношения базируются на взаимном обмене } \\
\text { знаниями, инновациях и взаимодействии с по- } \\
\text { требителями. }\end{array}$ \\
\hline $\begin{array}{l}\text { Вертикальные иерархия, ли- } \\
\text { дерство, менеджмент. }\end{array}$ & $\begin{array}{l}\text { Предприятие как гибкая сеть, построенная на } \\
\text { сотрудничестве и обмене знаниями. }\end{array}$ \\
\hline $\begin{array}{l}\text { Вертикальная структура, } \\
\text { жесткая функциональность. }\end{array}$ & $\begin{array}{l}\text { Плоская структура, ориентированная на про- } \\
\text { ект и потребителя. }\end{array}$ \\
\hline $\begin{array}{l}\text { Лидерство как позиция в } \\
\text { вертикальной иерархии. }\end{array}$ & Лидерство через опыт и знания. \\
\hline $\begin{array}{l}\text { Менеджер функциональ- } \\
\text { ного направления. }\end{array}$ & Менеджер проекта. \\
\hline Карьерная культура. & Инновационная культура. \\
\hline $\begin{array}{l}\text { Позиции и должности четко } \\
\text { определены. }\end{array}$ & $\begin{array}{l}\text { Позиции определены, но специалисты мо- } \\
\text { бильны. }\end{array}$ \\
\hline Процессный принцип. & Проектный принцип. \\
\hline
\end{tabular}


Таблица 4. Новые формы контрактных отношений с персоналом в обрабатывающей промышленности. По данным (2017-2019) Deloitte. Обозн.: «Ч» - данные автора о наблюдениях применения формы контрактов в российском сегменте промышленности

\begin{tabular}{|l|l|c|}
\hline Форма & Содержание & $\begin{array}{l}\text { Ч, } \\
\%\end{array}$ \\
\hline $\begin{array}{l}\text { «Свобод- } \\
\text { ный кон- }\end{array}$ & $\begin{array}{l}\text { Договор подряда, частичная занятость, аутстаффинг и дру- } \\
\text { гие формы отношения с персоналом, подразумевающие } \\
\text { разделение рабочего времени сотрудника между разными } \\
\text { хозяйствующими субъектами, в т. ч. конкурентами. }\end{array}$ & 65 \\
\hline $\begin{array}{l}\text { «Спин- } \\
\text { офф» }\end{array}$ & $\begin{array}{l}\text { Выделение функции хозяйствующего субъекта в дочер- } \\
\text { нюю организацию, с включением в число акционеров (до- } \\
\text { черней) ключевых функциональных сотрудников. }\end{array}$ & 5 \\
\hline «Опцион» & $\begin{array}{l}\text { Предоставление ключевым сотрудникам в качестве возна- } \\
\text { граждения акций хозяйствующего субъекта. }\end{array}$ & 15 \\
\hline $\begin{array}{l}\text { «Танть- } \\
\text { ема» }\end{array}$ & $\begin{array}{l}\text { Мотивация ключевых сотрудников из чистой прибыли } \\
\text { предприятия, вариативно размеру годовому результату. }\end{array}$ & 15 \\
\hline
\end{tabular}

Таблица 5. Дефицитные («Д») знания, навыки и способности персонала (первая десятка) на рынке труда. Интерпретирована автором по OECD [9]

\begin{tabular}{|c|c|c|c|c|c|}
\hline \multicolumn{2}{|l|}{ Области знаний } & \multicolumn{2}{|l|}{ Навыки и умения } & \multicolumn{2}{|l|}{ Способности } \\
\hline Структура & Д & Структура & Д & Структура & Д/П \\
\hline $\begin{array}{ll}\text { Компьютеры } \\
\text { электроника }\end{array}$ & +27 & $\begin{array}{l}\text { Суждение и приня- } \\
\text { тие решений }\end{array}$ & +20 & Вербальные & +25 \\
\hline $\begin{array}{l}\text { Образование и } \\
\text { обучение }\end{array}$ & +25 & Саморазвитие & +19 & $\begin{array}{l}\text { Аргументиро- } \\
\text { вание }\end{array}$ & +18 \\
\hline Психология & +21 & Системный анализ & +18 & $\begin{array}{l}\text { Математиче- } \\
\text { ские }\end{array}$ & +12 \\
\hline Математика & +18 & Умение обучать & +17 & Память & +11 \\
\hline $\begin{array}{l}\text { Консультирова- } \\
\text { ние }\end{array}$ & +17 & $\begin{array}{ll}\begin{array}{l}\text { Социальная } \\
\text { спективность }\end{array} & \text { пер- } \\
\end{array}$ & +17 & Восприятие & +9 \\
\hline $\begin{array}{l}\text { Социология и ан- } \\
\text { тропология }\end{array}$ & +15 & Тайм менеджмент & +14 & $\begin{array}{l}\text { Вниматель- } \\
\text { ность }\end{array}$ & +7 \\
\hline Право & +15 & $\begin{array}{l}\text { Операционный ана- } \\
\text { лиз }\end{array}$ & +14 & $\begin{array}{l}\text { Вербальные } \\
\text { (аудиторные) }\end{array}$ & +6 \\
\hline $\begin{array}{l}\text { Администриро- } \\
\text { вание и управле- } \\
\text { ние }\end{array}$ & +13 & $\begin{array}{l}\text { Персональный (ре- } \\
\text { сурсный) менедж- } \\
\text { мент }\end{array}$ & +12 & $\begin{array}{l}\text { Наблюдатель- } \\
\text { ность }\end{array}$ & +2 \\
\hline $\begin{array}{l}\text { Медицина и сто- } \\
\text { матология }\end{array}$ & +12 & $\begin{array}{l}\text { Координирован- } \\
\text { ность }\end{array}$ & +12 & & \\
\hline Сервис & +9 & Убедительность & +12 & & \\
\hline
\end{tabular}


Расширение применения принципов концепции Индустрии 4.0» в обрабатывающей промышленности увеличит дефицит специалистов необходимого профиля и профицит с устаревшими знаниями, навыками и способностями. «... Текущие рабочие места в производстве сталкиваются с высоким риском автоматизации ... Численность рабочих будет убывать. Оставшиеся рабочие места будут ориентированы на работу с информацией, а содержание работ ориентировано на среднесрочные и сложные задачи...» (Stock T. и др. [13]).

Объективен перспективный профиль человеческого капитала (табл. 5): знания инфокоммуникаций, интеллектуальные навыки и социальные способности. В этом контексте выражена задача, стоящая перед предприятиями обрабатывающей промышленности - инвестиции в создание новой формации персонала и партнерской модели взаимодействия.

Обобщая 3 представленные перспективы, автор делает вывод об изменении ключевого принципа производственных отношений в обрабатывающей промышленности: от марксистской прибавочной стоимости от наемного работника к бенефициару инновационного проекта. Это объективно видно по изменению структуры капиталовложений обрабатывающей промышленности (рис. 1): от доминирования основных фондов в период 1970-2000 год к инвестированию в человеческий капитал $-54 \%$ в 2025 году (в совокупности направлений - образование, здравоохранение, мобильность).

В данной позиции солидарны: предприниматели (рис. 1); ученые («...роль человеческого капитала как ключевой фактор, объясняющий, почему некоторые фирмы превосходят другие», Acedo F.J. и др. [14]); органы власти - одним из направлений экономического роста Правительства РФ видит «...увеличение человеческого капитала в промышленности...»*.

Выделенные перспективы трансформации производственных отношений являются «неизбежными» для обрабатывающей промышленности всех стран в силу усиления глобализации и роста темпов мобильности человеческого капитала. Модернизация основных фондов, переход к цифровым технологиям (определяющих конкурентоспособность, экономическую эффективность производственных процессов) невозможны без персонала с новым профилем знаний и навыков. А построение контрактных отноше-

* Распоряжение Правительства РФ от 6 июня 2020 г. № 1512-р Об утверждении «Сводной стратегии развития обрабатывающей промышленности РФ до 2024 г. и на период до 2035 г.».

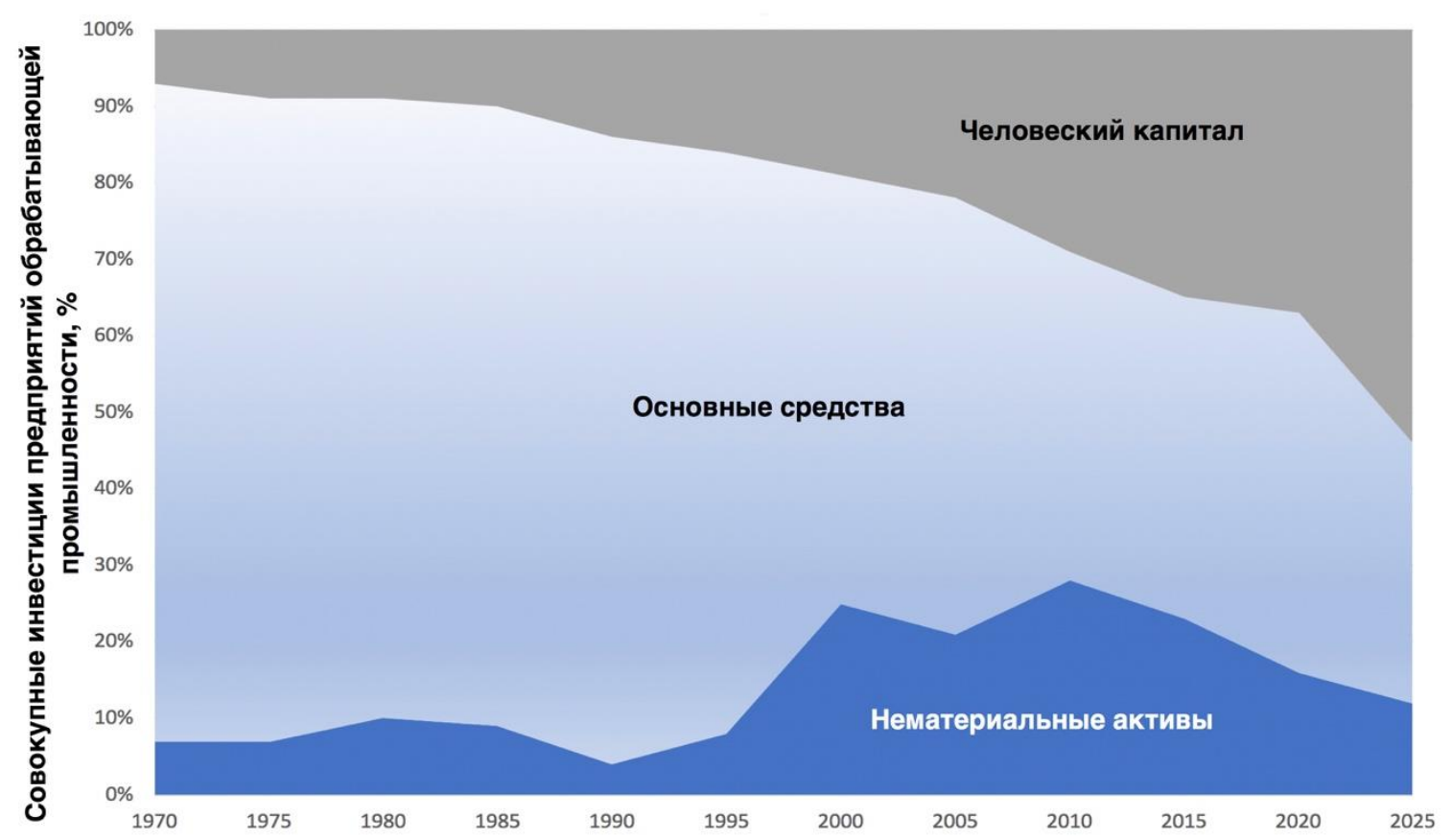

Puc. 1. Структура инвестиций обрабатывающей промышленности (2025 -прогноз). Составлено автором по данным OECD [8], Deloitte [4] 
ний с новым поколением «сотрудников» (автору импонирует в настоящем контексте данный термин как наиболее близкий по смысловой нагрузке - «партнер») невозможно на устаревших принципах «работник - работодатель». В практической проекции для предприятий обрабатывающей промышленности актуальны: переход от «процессной» к «проектной» модели организации хозяйственной деятельности с фокусом на инновационных решениях; формирование инвестиционного потенциала для перевода всех технологических и бизнес-процессов на цифровую платформу; (последнее по списку, но не по важности) разработка новых моделей взаимоотношений с ключевыми сотрудниками предприятия (которые собственно и рассматриваются как человеческий капитал на микроуровне).

\section{Библиографический список}

1. Glossary of Environment Statistics, Studies in Methods, Series F, No. 67, United Nations, New York, 1997.

2. Coff, R. W. Human assets and management dilemmas: Coping with hazards on the road to resource-based theory. Academy of Management Review, 22, 1997, 374-403.

3. The Global Human Capital Report 2017. World Economic Forum, 2017. Электронный документ. Режим доступа: https://www.weforum.org/reports/the-global-human-capital-report-2017 12.12.2019.

4. 2019 Global Human Capital Trends. Deloitte University Press, 2017. Электронный документ. Режим доступа: https://www2.deloitte.com/us/en/insights/focus/human-capital-trends.html 22.01.2020.

5. Leading the social enterprise - Reinvent with a human focus. 2019 Global Human Capital Trends, Deloitte 2020. Электронный документ. Режим доступа: https:/www2.deloitte.com/us/en/insights/focus/human-capitaltrends/2019/leading-social-enterprise.html 29.04.2020.

6. Насколько богата Россия? Оценка совокупного уровня благосостояния России в период с 2000 по 2017 годы (русский) / Sanghi, Apurva; Lange, Glenn-Marie; Naikal, Esther G.; Emelyanova, Olga; Nemova, Vladislava I.; Rostovtseva, Irina / Доклад № 141790. Всемирный Банк, 2019. Электронный документ. Режим доступа: http:// documents.vsemirnyjbank.org/curated/ru/402431575351416107/How-Wealthy-is-Russia-Measuring-RussiasComprehensive-Wealth-from-2000-2017 12.04.2020.

7. Science, research and innovation performance of the EU, 2018. Strengthening the foundations for Europe's future. EU publications, 2019. Электронный документ. Режим доступа: https://op.europa.eu/en/publication-detail/-/ publication/16907d0f-1d05-11e8-ac73-01aa75ed71a1/language-en 23.04.2020.

8. OECD Employment Outlook 2019: The Future of Work, OECD Publishing, Paris, 2019. Электронный документ. Режим доступа: https:/www.oecd.org/employment/outlook/ 22.06.2020.

9. OECD Skills Outlook 2019: Thriving in a Digital World, OECD Publishing, 2019. Электронный документ. Режим доступа: https://www.oecd-ilibrary.org/docserver/9789264313835-en.pdf?expires=1593425823\&id=id\&accname =guest \&checksum=87A773B787587FD6C2BE83F486460BA9 22.06.2020.

10. 2020 Manufacturing Industry Outlook. Exploring manufacturing trends, Delloite, 2019. Электронный документ. Режим доступа: https:/www2.deloitte.com/content/dam/Deloitte/us/Documents/energy-resources/ us-2020-manufacturing-outlook.pdf 20.06.2020.

11. Архипов А.Ю., Козлова Е. В. Национальная миграционная политика в динамике глобализации рынка труда. Монография. Ростов н/Д: Изд-во «Содействие-XXI век», 2016. - 176 с.

12. Brown, A. W., Adams, J. D., \& Amjad, A. A. The relationship between human capital and time performance in project management: A path analysis. International Journal of Project Management, 25, 2007, 77-89.

13. Stock, T., \& Seliger, G. Opportunities of Sustainable Manufacturing in Industry 4.0. Procedia CIRP, 40, 2016, 536541.

14. Acedo, F.J., Barroso, C., Galan, J.L. The resource-based theory: Dissemination and main trends. Strategic Management Journal, 27, 2006 